\title{
Association of Polymorphisms in the Glutathione S-Transferase Theta-1 Gene with Cirrhosis and Hepatocellular Carcinoma in Brazilian Patients with Chronic Hepatitis C
}

\author{
Oscar C. Araujo ${ }^{1}$, Vanessa S. de Paula ${ }^{1}$, Kycia M. do Ó ${ }^{2}$, Cristiane A. Villela-Nogueira ${ }^{3}$ \\ and Natalia M. Araujo 1,*(D) \\ 1 Laboratory of Molecular Virology, Oswaldo Cruz Institute, FIOCRUZ, Rio de Janeiro 21040-360, Brazil; \\ araujo.orc@gmail.com (O.C.A.); vdepaula@ioc.fiocruz.br (V.S.d.P.) \\ 2 São Lucas Hospital, Petrópolis 25660-290, Brazil; kyciadoo@gmail.com \\ 3 Hepatology Division, Clementino Fraga Filho University Hospital, School of Medicine, \\ Federal University of Rio de Janeiro, Rio de Janeiro 21941-617, Brazil; crisvillelanog@gmail.com \\ * Correspondence: nmaraujo@ioc.fiocruz.br
}

\section{check for} updates

Citation: Araujo, O.C.; de Paula, V.S.; do Ó, K.M.; Villela-Nogueira, C.A.; Araujo, N.M. Association of Polymorphisms in the Glutathione S-Transferase Theta-1 Gene with Cirrhosis and Hepatocellular Carcinoma in Brazilian Patients with Chronic Hepatitis C. Vaccines 2021, 9, 831. https://doi.org/

$10.3390 /$ vaccines 9080831

Academic Editor: Ruchi Shukla

Received: 18 June 2021

Accepted: 20 July 2021

Published: 29 July 2021

Publisher's Note: MDPI stays neutral with regard to jurisdictional claims in published maps and institutional affiliations.

Copyright: (c) 2021 by the authors. Licensee MDPI, Basel, Switzerland. This article is an open access article distributed under the terms and conditions of the Creative Commons Attribution (CC BY) license (https:/ / creativecommons.org/licenses/by/ $4.0 /)$.

\begin{abstract}
Oxidative stress contributes to hepatitis C virus (HCV)-induced liver damage. Host genetic factors may be involved in progression of HCV infection. The present study was conducted to determine the influence of glutathione S-transferase (GST)-M1 and T1 gene polymorphisms during different stages of HCV infection, including chronic hepatitis, cirrhosis, and hepatocellular carcinoma (HCC). The study population comprised 190 patients (47 with chronic hepatitis, 83 with cirrhosis (without HCC), and 60 with HCC). GSTM1 and GSTT1 gene polymorphisms were analyzed via multiplex polymerase chain reaction. The GSTT1-null genotype was more commonly detected in patients with cirrhosis $(n=17 ; 20.5 \%)$ and HCC $(n=13 ; 21.7 \%)$ than those with chronic hepatitis $(n=3$; $6.4 \%$ ). The differences in GSTT1-null genotype frequencies were significant for cirrhosis vs. chronic hepatitis (odds ratio, OR, 3.778 (95\% confidence interval, CI, 1.045-13.659); $p=0.043$ ) and HCC vs. chronic hepatitis (OR, 4.057 (95\% CI, 1.083-15.201); $p=0.038$ ) groups. However, the incidence of individual GSTM1-null or combined GSTM1/ GSTT1 double-null genotypes did not vary significantly between the groups. Our collective findings support the utility of the GSTT1-null genotype as a useful biomarker for liver disease progression in Brazilian patients with chronic hepatitis $\mathrm{C}$.
\end{abstract}

Keywords: hepatitis C virus; glutathione S-transferases; cirrhosis; hepatocellular carcinoma; polymorphisms

\section{Introduction}

With a reported 905,677 new cases and 830,180 deaths in 2020, liver cancer is predicted to be the sixth leading cause of cancer and third highest cause of cancer-associated mortality worldwide, presenting a major global health problem [1]. Hepatocellular carcinoma (HCC) is the most common form of liver malignancy and accounts for $\sim 90 \%$ of cases [2]. In most cases, HCC develops in the context of chronic liver inflammation and cirrhotic transformation, due to viral hepatitis, alcohol abuse, or nonalcoholic fatty liver disease [3]. Cirrhosis of any etiology is a main risk factor for development of HCC. Among cirrhotic patients, those with hepatitis $\mathrm{C}$ virus $(\mathrm{HCV})$ infection have the highest risk of developing HCC, even after viral eradication [4]. In Brazil, 10,902 deaths were attributed to HCC in 2019 [5], the major risk factor being chronic HCV infection, which accounted for $\sim 65 \%$ of the cases [6].

According to the World Health Organization (WHO), an estimated 71 million people worldwide have chronic HCV infection, resulting in 399,000 deaths, mainly attributable to cirrhosis and HCC [7]. Despite tremendous improvements in HCV treatment in recent years, many patients remain at risk of disease progression to cirrhosis and HCC $[8,9]$. 
Disease progression is influenced by viral, genetic, and epigenetic factors [10]. Numerous candidate-gene studies have reported associations between genetic polymorphisms and the presence of HCC [11-15]. Since oxidative stress is a critical factor in the pathogenesis of chronic hepatitis C [16], genetically induced differences in antioxidant mechanisms may modulate the natural history of the disease.

Glutathione S-transferases (GST) consist of an essential enzymatic system implicated in the cellular mechanism of detoxification that protects cells against oxidative stress. At least seven different classes of GSTs are highly expressed in the mammalian liver. GSTM1 and GSTT1 activities are modulated by genetic polymorphisms, and these isoforms are the most extensively studied in relation to risk of environment-related human diseases. GST Mu class (GSTM1) is located on the short arm of chromosome 1 (1p13.3) and GST Theta class (GSTT1) is on the long arm of chromosome $22(22 q 11.23)[17,18]$. Both genes have a null variant allele (partially deleted), which results in abrogation of catalytic activity and consequent enhancement of oxidative stress and cytotoxic damage in the liver. Individuals carrying homozygous deletions in these genes are considered to be at higher risk for malignancy, owing to their reduced capacity to detoxify potential carcinogens [19]. Previous studies support an association between GSTM1 and GSTT1 polymorphisms and risk of HCC (including both viral and non-viral etiologies). However, the majority of these studies were performed in Asian populations [20-22].

Limited published data are available on the influence of GST polymorphisms in the late stages of HCV infection, specifically, development of cirrhosis and HCC [23-25], and no studies have been conducted on the Brazilian population to date. In this study, we determined the distribution of GSTM1 and GSTT1 polymorphisms in patients with chronic HCV grouped according to stage of liver disease (chronic hepatitis, cirrhosis, and HCC), with a view to investigating their potential involvement in risk of disease progression in Brazilian patients with chronic hepatitis $\mathrm{C}$ infection.

\section{Materials and Methods}

\subsection{Patients}

Blood samples were collected from 190 patients with HCV chronic infection at different stages of liver disease, including 47 with chronic hepatitis, 83 with cirrhosis (without HCC), and 60 with HCC, referred to the Clementino Fraga Filho University Hospital (HUCFF) in Rio de Janeiro, Brazil, from 2012 to 2015. Cases with viral co-infections (hepatitis B virus, hepatitis A virus, hepatitis E virus, human immunodeficiency virus), alcoholics, and those with other etiologies for chronic liver diseases were excluded. Diagnosis of liver cirrhosis was based on liver biopsy or presence of clinical and laboratory features of portal hypertension at ultrasound or upper endoscopy. HCC diagnosis was made based on at least one positive image on magnetic resonance imaging or computed tomography. Demographic, laboratory, and clinical data were obtained from the medical records of patients. The research protocol was approved by the Ethics Committee of the hospital (agreement number 139/10) and informed consent was obtained from all patients.

\subsection{Genotyping of GSTM1 and GSTT1 Polymorphisms}

Genomic DNA was extracted from $200 \mu \mathrm{L}$ aliquots of serum samples using the High Pure Viral Nucleic Acid kit (Roche Diagnostics, Basel, Switzerland) according to the manufacturer's instructions. GSTM1 and GSTT1 polymorphisms were detected based on multiplex polymerase chain reaction (PCR) using $\beta$-globin as an internal control according to the report of Unal et al. [26]. Briefly, a $50 \mu \mathrm{L}$ multiplex reaction mixture, containing $4 \mu \mathrm{L}$ nucleic acid template, 2U Platinum Taq DNA Polymerase, 10 pmol forward and reverse primers and supplied reagents (Invitrogen, Waltham, MA, USA), was used for PCR. Amplification conditions comprised 35 cycles of denaturation at $94{ }^{\circ} \mathrm{C}$ for $1 \mathrm{~min}$, annealing at $62{ }^{\circ} \mathrm{C}$ for $1 \mathrm{~min}$, and extension at $72{ }^{\circ} \mathrm{C}$ for $1 \mathrm{~min}$, resulting in a fragment of $480 \mathrm{bp}$ for GSTT1, $215 \mathrm{bp}$ for GSTM1, and $268 \mathrm{bp}$ for $\beta$-globin. PCR reactions were performed on an ABI 2720 Thermal Cycler (Applied Biosystems, Waltham, MA, USA). 
A negative control containing water instead of DNA was included in all amplification reactions. PCR products were analyzed on a $2 \%$ agarose gel and stained with ethidium bromide (Figure 1). The subjects were classified as either positive (when at least one copy of the gene was present) or null genotypes. Heterozygous and homozygous individuals for GSTM1 or GSTT1 have been reported to present similar enzyme expression levels [27] and were considered together for statistical analysis.

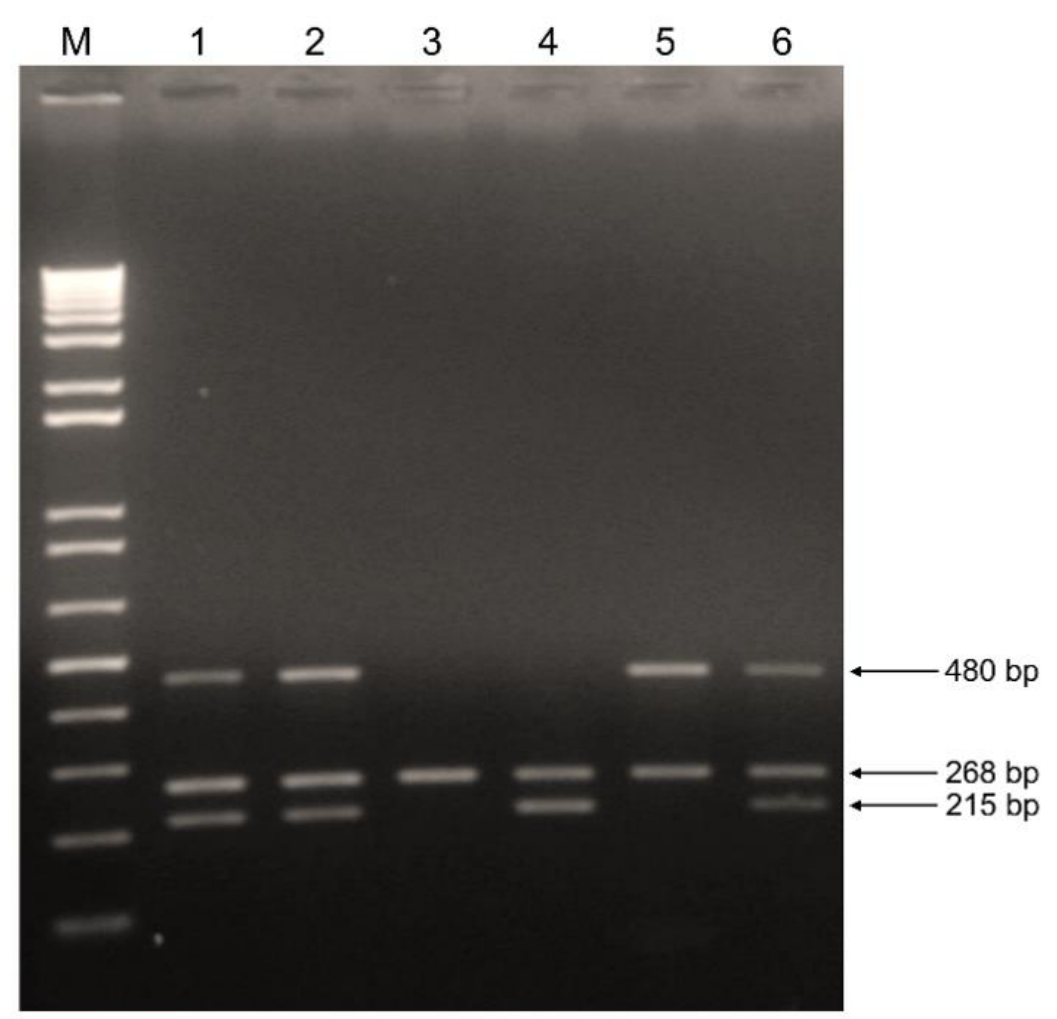

Figure 1. Genotyping of GSTM1 and GSTT1 by multiplex PCR. Lane M: 1 Kb Plus DNA Ladder. Lanes 1, 2 and 6: positive GSTM1 and GSTT1 genotypes. Lane 3: null GSTM1 and GSTT1 genotypes (absence of 215 and $480 \mathrm{bp}$ fragments). Lane 4: null GSTT1 genotype (absence of $480 \mathrm{bp}$ fragment). Lane 5: null GSTM1 genotype (absence of $215 \mathrm{bp}$ fragment). The $\beta$-globin internal control is detected as $268 \mathrm{bp}$ fragment.

\subsection{Statistical Analysis}

Statistical analysis using SPSS 20.0 software (IBM, Armonk, NY, USA) was performed to calculate odds ratio (OR) and 95\% confidence intervals (CI) to assess the relative disease risk conferred by a specific genotype. Polymorphism distribution and categorical variables of patient data were compared using Pearson's $\chi^{2}$ or Fisher's exact test, as appropriate. Mann-Whitney and Student's t-test were used to compare quantitative variables between groups. $p$-values $<0.05$ were considered statistically significant.

\section{Results}

\subsection{Characteristics of Patients}

Table 1 shows the demographic and biochemical characteristics of $190 \mathrm{HCV}$-infected patients classified as chronic hepatitis, cirrhosis (without HCC), and HCC carriers. The mean age of HCC patients was significantly higher than that of patients with chronic hepatitis $(p<0.001)$ and cirrhosis $(p=0.006)$. The group with chronic hepatitis had a lower proportion of males, compared to the HCC $(p=0.015)$ group. No statistically significant differences were detected between HCC and cirrhosis groups in relation to sex and levels of alanine aminotransferase (ALT), aspartate aminotransferase (AST), alkaline phosphatase (ALP), gamma-glutamyl transpeptidase (GGT), serum albumin (ALB), and total bilirubin 
(T.BIL). However, the group with chronic hepatitis had significantly lower ALT, AST, ALP, GGT, and T.BIL values than the HCC group ( $p<0.05$ for all observations). Moreover, alpha-fetoprotein (AFP) levels were significantly higher in HCC patients than those with cirrhosis and chronic hepatitis $(p<0.01$ for both). Data on HCV genotypes were available for $131(69 \%)$ patients. The frequencies of genotypes $1 \mathrm{a}, 1 \mathrm{~b}$, and $3 \mathrm{a}$ in the total group were $45 \%, 41 \%$ and $14 \%$, respectively. No significant differences were observed between HCC, cirrhosis, and chronic hepatitis groups in relation to HCV genotype (Table 1).

Table 1. Demographic and laboratory data on HCV-infected patients.

\begin{tabular}{|c|c|c|c|c|c|c|}
\hline \multirow[b]{2}{*}{ Characteristics } & \multirow[b]{2}{*}{$\begin{array}{l}\text { Chronic Hepatitis } \\
\quad(n=47)\end{array}$} & \multirow[b]{2}{*}{$\begin{array}{l}\text { Cirrhosis } \\
(n=83)\end{array}$} & \multirow[b]{2}{*}{$\begin{array}{c}\text { HCC } \\
(n=60)\end{array}$} & \multicolumn{3}{|c|}{$p$-Value } \\
\hline & & & & $\begin{array}{c}\text { HCC } \\
\text { vs. } \\
\text { Chronic Hepatitis }\end{array}$ & $\begin{array}{l}\text { HCC } \\
\text { vs. } \\
\text { Cirrhosis }\end{array}$ & $\begin{array}{c}\text { Cirrhosis } \\
\text { vs. } \\
\text { Chronic Hepatitis }\end{array}$ \\
\hline Age $(\text { years, mean } \pm S D)^{a}$ & $57 \pm 11$ & $59 \pm 9$ & $64 \pm 9$ & $<0.001$ & 0.006 & 0.48 \\
\hline Male $(\%)$ & $14(30)$ & $42(51)$ & $32(53)$ & 0.015 & 0.74 & 0.99 \\
\hline ALT (U/L, median (IQR)) & $59(41)$ & $74(75)$ & $82(30)$ & 0.029 & 0.88 & 0.067 \\
\hline AST (U/L, median (IQR)) & $43(40)$ & 70 (77) & $91(62)$ & 0.001 & 0.30 & 0.008 \\
\hline ALP (U/L, median (IQR)) & $80(35)$ & $110(58)$ & $123(134)$ & $<0.01$ & 0.18 & $<0.01$ \\
\hline GGT (U/L, median (IQR)) & $68(46)$ & $101(146)$ & $113(155)$ & 0.002 & 0.32 & 0.012 \\
\hline ALB (g/dL, median (IQR)) & $3.8(0.4)$ & $3.6(1.0)$ & $3.6(1.0)$ & 0.70 & 0.74 & 0.018 \\
\hline T.BIL (mg/dL, median (IQR)) & $0.7(0.3)$ & $0.8(0.8)$ & $0.9(0.6)$ & 0.005 & 0.40 & 0.016 \\
\hline AFP (ng/mL, median (IQR)) & $6.9 \pm(7.4)$ & $6.0(15)$ & $31(248)$ & $<0.01$ & $<0.01$ & 0.52 \\
\hline HCV genotype $(\%)$ & & & & & & \\
\hline $1 \mathrm{a}$ & $10(21)$ & $31(37)$ & $18(30)$ & 0.378 & 0.378 & 0.076 \\
\hline $1 \mathrm{~b}$ & $15(32)$ & $20(24)$ & $19(32)$ & 1.000 & 0.345 & 0.411 \\
\hline $3 a$ & $4(9)$ & $5(6)$ & $9(15)$ & 0.380 & 0.091 & 0.722 \\
\hline ND & $18(38)$ & 27 (33) & $14(23)$ & - & - & - \\
\hline
\end{tabular}

a One-way ANOVA, Bonferroni post hoc test. ALT, alanine aminotransferase; AST, aspartate aminotransferase; ALP, alkaline phosphatase; GGT, gamma-glutamyl transpeptidase; ALB, serum albumin; T.BIL, total bilirubin; AFP, alpha-fetoprotein; SD, standard deviation; IQR, interquartile range; ND, not determined.

\subsection{GSTM1 and GSTT1 Polymorphisms and Risk for Cirrhosis and HCC}

The distribution frequencies of GSTM1 and GSTT1-null genotypes between patients with cirrhosis and chronic hepatitis are presented in Table 2. The incidence of the GSTT1null genotype was significantly increased in patients with cirrhosis relative to the chronic hepatitis group (odds ratio, OR, 3.778 (95\% confidence interval, CI, 1.045-13.659); $p=0.043$ ). No significant differences were observed for individual GSTM1-null and combined GSTM1 / GSTT1 double-null genotypes (Table 2).

Table 2. Distribution of GSTM1 and GSTT1-null genotypes according to presence/absence of cirrhosis.

\begin{tabular}{cccccc}
\hline Genotype & Chronic Hepatitis $(\boldsymbol{n}=\mathbf{4 7})$ & Cirrhosis $(\boldsymbol{n}=\mathbf{8 3})$ & $\boldsymbol{p}$-Value & OR & $\mathbf{9 5 \%}$ CI \\
\hline GSTM1-null (\%) & $22(46.8 \%)$ & $34(41 \%)$ & 0.518 & 1.268 & $0.617-2.618$ \\
GSTT1-null (\%) & $3(6.4 \%)$ & $17(20.5 \%)$ & 0.043 & 3.778 & $1.045-13.659$ \\
GSTM1-null/GSTT1-null (\%) & $1(2.1 \%)$ & $3(3.6 \%)$ & 0.567 & 1.522 & $0.193-20.131$ \\
\hline
\end{tabular}

OR, odds ratio; $95 \% \mathrm{CI}, 95 \%$ confidence interval.

Table 3 shows the distribution of GSTM1 and GSTT1-null genotypes between patients with HCC and chronic hepatitis. A markedly higher frequency of GSTT1-null genotype was observed in HCC than chronic hepatitis patients (OR, 4.057 [95\% CI, 1.083-15.201]; $p=0.038$ ). We observed no significant differences with regard to other genotypes, although GSTM1/GSTT1 double-null genotype was more frequently detected in HCC patients than in those with chronic hepatitis ( $10 \%$ and $2.1 \%$, respectively).

Table 3. Distribution of GSTM1 and GSTT1-null genotypes according to presence/absence of HCC.

\begin{tabular}{cccccc}
\hline Genotype & Chronic Hepatitis $(\boldsymbol{n}=\mathbf{4 7 )}$ & HCC $(\boldsymbol{n}=\mathbf{6 0})$ & $\boldsymbol{p}$-Value & OR & $\mathbf{9 5 \%}$ CI \\
\hline GSTM1-null (\%) & $22(46.8 \%)$ & $28(46.7 \%)$ & 0.98 & 1.006 & $0.468-2.162$ \\
GSTT1-null (\%) & $3(6.4 \%)$ & $13(21.7 \%)$ & 0.038 & 4.057 & $1.083-15.201$ \\
GSTM1-null/GSTT1-null (\%) & $1(2.1 \%)$ & $6(10 \%)$ & 0.127 & 5.520 & $0.617-49.393$ \\
\hline
\end{tabular}


Analysis of liver biochemistry tests according to GSTM1 and GSTT1 genotypes is shown in Table 4. ALT, AST, ALP, GGT, ALB and T.BIL levels were not significantly different between genotypes $(p>0.05)$. Similarly, no significant differences in levels among the genotypes were detectable when patients from chronic hepatitis, cirrhosis, and HCC groups were analyzed individually (data not shown).

Table 4. Levels of liver biochemistry tests according to GSTM1 and GSTT1 genotypes.

\begin{tabular}{|c|c|c|c|c|c|c|}
\hline \multirow[b]{2}{*}{ Variables } & \multirow[b]{2}{*}{$\begin{array}{c}\text { GSTM1 } \\
\text { Null }\end{array}$} & \multirow[b]{2}{*}{$\begin{array}{l}\text { GSTM1 } \\
\text { Positive }\end{array}$} & \multirow[b]{2}{*}{$\begin{array}{c}\text { GSTT1 } \\
\text { Null }\end{array}$} & \multirow[b]{2}{*}{$\begin{array}{c}\text { GSTT1 } \\
\text { Positive }\end{array}$} & \multicolumn{2}{|c|}{$p$-Value } \\
\hline & & & & & $\begin{array}{c}\text { GSTM1 Null } \\
\text { vs. } \\
\text { GSTM1 Positive }\end{array}$ & $\begin{array}{c}\text { GSTT1 Null } \\
\text { vs. } \\
\text { GSTT1 Positive }\end{array}$ \\
\hline ALT (U/L, median (IQR)) & $78(67)$ & $71(45)$ & $77(42)$ & $71(59)$ & 0.283 & 0.907 \\
\hline AST (U/L, median (IQR)) & $70(93)$ & $69(73)$ & $85(69)$ & $68(78)$ & 0.279 & 0.748 \\
\hline $\operatorname{ALP}(\mathrm{U} / \mathrm{L}$, median (IQR)) & $97(54)$ & $107(79)$ & $116(72)$ & $103(76)$ & 0.074 & 0.206 \\
\hline GGT (U/L, median (IQR)) & 85 (181) & $102(130)$ & 89 (113) & $94(141)$ & 0.692 & 0.937 \\
\hline ALB (g/dL, median (IQR)) & $4.0(1.0)$ & $4.0(1.0)$ & $3.0(1.2)$ & $4.0(0.8)$ & 0.913 & 0.173 \\
\hline T.BIL (mg/dL, median (IQR)) & $1.0(0.9)$ & $1.0(0.5)$ & $1.0(0.9)$ & $1.0(0.7)$ & 0.420 & 0.839 \\
\hline
\end{tabular}

ALT, alanine aminotransferase; AST, aspartate aminotransferase; ALP, alkaline phosphatase; GGT, gamma-glutamyl transpeptidase; ALB, serum albumin; T.BIL, total bilirubin; IQR, interquartile range.

\section{Discussion}

Although several studies indicate that GST genotypes are associated with HCC (including both viral and non-viral etiologies), variable results according to ethnicity have been obtained. In two recent meta-analyses [20,22], increased risk of HCC was observed in Asians with GSTM1 and GSTT1 single-null and GSTM1/GSTT1 double-null genotypes, while no significant differences were detected among Caucasians or Africans. These differences may be attributed to diverse living surroundings and inherited backgrounds of the studied populations.

The Brazilian population has a highly admixed genetic background [28], and candidate gene-based association studies exploring the relationship between genetic polymorphisms and HCC are rare in Brazil. Since oxidative stress plays an important role in the pathogenesis of chronic hepatitis C [16], genetically induced differences in antioxidant mechanisms may influence disease severity. To our knowledge, the present study is the first to investigate the association of GSTM1 and GSTT1 polymorphisms with advanced liver disease induced by HCV infection in Brazilian patients. Our results suggest that the GSTT1-null genotype increases the risk of cirrhosis and HCC, since the frequency of this genotype was significantly higher in patients with cirrhosis (without HCC) and HCC relative to those with chronic hepatitis. Conversely, the frequency of the GSTM1-null genotype was similar in all groups and not associated with development of advanced liver disease in our study population. Our findings are consistent with a previous Brazilian study focusing on the association between GST polymorphisms and the risk of developing HCC (including both viral and non-viral etiologies), which showed that the GSTT1-null, but not GSTM1null genotype, was associated with HCC [29]. Likewise, significantly higher frequency of the GSTT1-null genotype was observed in Spanish patients with HCV-induced liver cirrhosis compared with healthy control subjects [24]. Interestingly, GSTT1 has glutathione peroxidase activity and may be directly involved in detoxification of reactive species produced as a consequence of ongoing HCV infection of the liver [24,30]. Notably, two previous studies evaluating the association of GSTM1 and GSTT1 polymorphisms with progression of liver disease in Egyptian [23] and Taiwanese [25] patients with chronic HCV showed considerably increased risk of advanced fibrosis in individuals with combined GSTM1/GSTT1 double-null genotype. Here, the GSTM1/GSTT1 double-null genotype was more frequently detected in patients with HCC than those with chronic hepatitis ( $10 \%$ vs. $2.1 \%$, respectively) but this difference was not statistically significant. Notably, the GSTT1-null genotype could induce a subtle but functionally significant deficit in hepatic 
antioxidant and reactive oxygen species (ROS)-inactivating mechanisms. The simultaneous lack of GSTM1 enzymatic function may reinforce this deficit, and consequently, more ROS and electrophilic compounds generated during HCV infection are present in individuals devoid of both GST enzymes [16,24]. The resulting deficit in antioxidant mechanisms may facilitate the amplification of the inflammatory reaction during chronic hepatitis $\mathrm{C}$ infection, increasing the risk of disease progression to cirrhosis and HCC.

We further investigated whether GSTM1 and GSTT1-null genotypes indirectly contribute to the levels of liver biochemistry tests (ALT, AST, ALP, GGT, ALB, T.BIL) in chronic $\mathrm{HCV}$ infection cases. No significant differences in the levels were observed between positive and null genotypes in the whole study population or upon individual analysis of patients with chronic hepatitis, cirrhosis, and HCC. To our knowledge, no previous studies have focused on the influence of GSTM1 and GSTT1 polymorphisms on liver biochemistry tests in chronic HCV infection. Potential limitations of this study include small sample size and older age of the patients with HCC.

Predisposition to disease severity based on genetic risk has been extensively explored as a path to personalized medicine. The ability of polymorphic traits, alone, to refine individual prognosis has been considered insufficient for introduction into clinical practice as predictive markers [11,14]. However, future integration of several panels of genes may define a "genomic risk prediction" and improve the existing risk-assessment models for HCC.

In conclusion, the GSTT1-null genotype was significantly more frequent in the most severe presentations of HCV-related liver disease among Brazilian patients, supporting its potential as a molecular marker for assessing risk of progression of chronic hepatitis $C$ to cirrhosis and HCC. However, further large-scale population-based studies are warranted to validate these findings.

Author Contributions: Conceptualization, O.C.A. and N.M.A.; methodology, O.C.A. and C.A.V.-N.; formal analysis, O.C.A., V.S.d.P., C.A.V.-N. and N.M.A.; resources, V.S.d.P., K.M.d.Ó., C.A.V.-N. and N.M.A.; writing — original draft preparation, O.C.A. and N.M.A.; writing-review and editing, O.C.A., V.S.d.P., K.M.d.Ó., C.A.V.-N. and N.M.A.; supervision, N.M.A.; funding acquisition, N.M.A. All authors have read and agreed to the published version of the manuscript.

Funding: This research was funded by Conselho Nacional de Desenvolvimento Científico e Tecnológico (CNPq), grant number 428676/2018-9, and Fundação de Amparo à Pesquisa do Estado do Rio de Janeiro (FAPERJ), grant number E-26/210.450/2019.

Institutional Review Board Statement: The study was conducted according to the guidelines of the Declaration of Helsinki, and approved by the Ethics Committee of the Clementino Fraga Filho University Hospital (HUCFF) (protocol code 139/10 and date of approval 10 December 2010).

Informed Consent Statement: Informed consent was obtained from all subjects involved in the study.

Acknowledgments: We thank Flavia Savassi for her help in collecting patient data from the medical records.

Conflicts of Interest: The authors declare no conflict of interest.

\section{References}

1. IARC. International Agency for Research on Cancer. Globocan 2020. 11-Liver-Fact-Sheet.pdf. Available online: https://gco.iarc. $\mathrm{fr} /$ today / data/factsheets/cancers /11-Liver-fact-sheet.pdf (accessed on 13 May 2021).

2. $\quad$ Llovet, J.M.; Kelley, R.K.; Villanueva, A.; Singal, A.G.; Pikarsky, E.; Roayaie, S.; Lencioni, R.; Koike, K.; Zucman-Rossi, J.; Finn, R.S. Hepatocellular carcinoma. Nat. Rev. Dis. Primers 2021, 7, 6. [CrossRef] [PubMed]

3. Fujiwara, N.; Friedman, S.L.; Goossens, N.; Hoshida, Y. Risk factors and prevention of hepatocellular carcinoma in the era of precision medicine. J. Hepatol. 2018, 68, 526-549. [CrossRef] [PubMed]

4. Fattovich, G.; Stroffolini, T.; Zagni, I.; Donato, F. Hepatocellular carcinoma in cirrhosis: Incidence and risk factors. Gastroenterology 2004, 127, S35-S50. [CrossRef]

5. INCA. Tipos de Câncer- =Câncer de Fígado. Instituto Nacional do Câncer, Ministério da Saúde. Available online: https: // www.inca.gov.br/tipos-de-cancer/cancer-de-figado (accessed on 8 March 2021). 
6. Paranagua-Vezozzo, D.C.; Ono, S.K.; Alvarado-Mora, M.V.; Farias, A.Q.; Cunha-Silva, M.; Franca, J.I.; Alves, V.A.; Sherman, M.; Carrilho, F.J. Epidemiology of HCC in Brazil: Incidence and risk factors in a ten-year cohort. Ann. Hepatol. 2014, 13, $386-393$. [CrossRef]

7. WHO. The World Health Organization. Fact Sheets. Hepatitis C. Available online: https://www.who.int/news-room/factsheets/detail/hepatitis-c (accessed on 13 May 2021).

8. Ravi, S.; Axley, P.; Jones, D.; Kodali, S.; Simpson, H.; McGuire, B.M.; Singal, A.K. Unusually High Rates of Hepatocellular Carcinoma after Treatment With Direct-Acting Antiviral Therapy for Hepatitis C Related Cirrhosis. Gastroenterology 2017, 152, 911-912. [CrossRef] [PubMed]

9. Roche, B.; Coilly, A.; Duclos-Vallee, J.C.; Samuel, D. The impact of treatment of hepatitis C with DAAs on the occurrence of HCC. Liver Int. Off. J. Int. Assoc. Study Liver 2018, 38 (Suppl. 1), 139-145. [CrossRef]

10. Kanda, T.; Goto, T.; Hirotsu, Y.; Moriyama, M.; Omata, M. Molecular Mechanisms Driving Progression of Liver Cirrhosis towards Hepatocellular Carcinoma in Chronic Hepatitis B and C Infections: A Review. Int. J. Mol. Sci. 2019, 20, 1358. [CrossRef]

11. Caruso, S.; O’Brien, D.R.; Cleary, S.P.; Roberts, L.R.; Zucman-Rossi, J. Genetics of Hepatocellular Carcinoma: Approaches to Explore Molecular Diversity. Hepatology 2021, 73 (Suppl. 1), 14-26. [CrossRef]

12. Kumar, V.; Kato, N.; Urabe, Y.; Takahashi, A.; Muroyama, R.; Hosono, N.; Otsuka, M.; Tateishi, R.; Omata, M.; Nakagawa, H.; et al. Genome-wide association study identifies a susceptibility locus for HCV-induced hepatocellular carcinoma. Nat. Genet. 2011, 43, 455-458. [CrossRef]

13. Miki, D.; Ochi, H.; Hayes, C.N.; Abe, H.; Yoshima, T.; Aikata, H.; Ikeda, K.; Kumada, H.; Toyota, J.; Morizono, T.; et al. Variation in the DEPDC5 locus is associated with progression to hepatocellular carcinoma in chronic hepatitis $\mathrm{C}$ virus carriers. Nat. Genet. 2011, 43, 797-800. [CrossRef]

14. Nahon, P.; Zucman-Rossi, J. Single nucleotide polymorphisms and risk of hepatocellular carcinoma in cirrhosis. J. Hepatol. 2012, 57, 663-674. [CrossRef]

15. Zhang, C.; Ye, Z.; Zhang, Z.; Zheng, J.; Tang, Y.; Hou, E.; Huang, Z.; Meng, L. A comprehensive evaluation of single nucleotide polymorphisms associated with hepatocellular carcinoma risk in Asian populations: A systematic review and network metaanalysis. Gene 2020, 735, 144365. [CrossRef] [PubMed]

16. Koike, K.; Miyoshi, H. Oxidative stress and hepatitis C viral infection. Hepatol. Res. Off. J. Jpn. Soc. Hepatol. 2006, 34, 65-73. [CrossRef] [PubMed]

17. Awasthi, Y.C.; Sharma, R.; Singhal, S.S. Human glutathione S-transferases. Int. J. Biochem. 1994, 26, 295-308. [CrossRef]

18. Hayes, J.D.; Flanagan, J.U.; Jowsey, I.R. Glutathione transferases. Annu. Rev. Pharmacol. Toxicol. 2005, 45, 51-88. [CrossRef] [PubMed]

19. McIlwain, C.C.; Townsend, D.M.; Tew, K.D. Glutathione S-transferase polymorphisms: Cancer incidence and therapy. Oncogene 2006, 25, 1639-1648. [CrossRef]

20. Li, S.; Xue, F.; Zheng, Y.; Yang, P.; Lin, S.; Deng, Y.; Xu, P.; Zhou, L.; Hao, Q.; Zhai, Z.; et al. GSTM1 and GSTT1 null genotype increase the risk of hepatocellular carcinoma: Evidence based on 46 studies. Cancer Cell Int. 2019, 19, 76. [CrossRef] [PubMed]

21. Liu, K.; Zhang, L.; Lin, X.; Chen, L.; Shi, H.; Magaye, R.; Zou, B.; Zhao, J. Association of GST genetic polymorphisms with the susceptibility to hepatocellular carcinoma (HCC) in Chinese population evaluated by an updated systematic meta-analysis. PLoS ONE 2013, 8, e57043. [CrossRef]

22. Shen, Y.H.; Chen, S.; Peng, Y.F.; Shi, Y.H.; Huang, X.W.; Yang, G.H.; Ding, Z.B.; Yi, Y.; Zhou, J.; Qiu, S.J.; et al. Quantitative assessment of the effect of glutathione S-transferase genes GSTM1 and GSTT1 on hepatocellular carcinoma risk. Tumour Biol. J. Int. Soc. Oncodevelopmental Biol. Med. 2014, 35, 4007-4015. [CrossRef]

23. Ibrahim, A.M.; Ahmed, H.S.; Alazizi, N.M.; Mansour, M.A.; Mansour, S.A. Glutathione S-Transferase M1 and T1 Gene Polymorphisms and the Outcome of Chronic Hepatitis C Virus Infection in Egyptian Patients. Ann. Hum. Genet. 2016, 80, 32-37. [CrossRef]

24. Martinez, C.; Garcia-Martin, E.; Ladero, J.M.; Herraez, O.; Ortega, L.; Taxonera, C.; Suarez, A.; Diaz-Rubio, M.; Agundez, J.A. GSTT1 and GSTM1 null genotypes may facilitate hepatitis C virus infection becoming chronic. J. Infect. Dis. 2007, 195, 1320-1323. [CrossRef] [PubMed]

25. Sun, F.C.; Jeng, Y.C.; Lee, M.S.; Wen, C.F.; Chen, T.M.; Lee, M.S. Glutathione-S-Transferase M1 and T1 Gene Polymorphisms and Susceptibility to the Progression of Liver Fibrosis in HCV-Infected Patients in Taiwan. J. Med. Biochem. 2014, 33, 259-264. [CrossRef]

26. Unal, M.; Guven, M.; Devranoglu, K.; Ozaydin, A.; Batar, B.; Tamcelik, N.; Gorgun, E.E.; Ucar, D.; Sarici, A. Glutathione S transferase M1 and T1 genetic polymorphisms are related to the risk of primary open-angle glaucoma: A study in a Turkish population. Br. J. Ophthalmol. 2007, 91, 527-530. [CrossRef]

27. Bell, D.A.; Taylor, J.A.; Paulson, D.F.; Robertson, C.N.; Mohler, J.L.; Lucier, G.W. Genetic risk and carcinogen exposure: A common inherited defect of the carcinogen-metabolism gene glutathione S-transferase M1 (GSTM1) that increases susceptibility to bladder cancer. J. Natl. Cancer Inst. 1993, 85, 1159-1164. [CrossRef]

28. Pena, S.D.J.; Santos, F.R.; Tarazona-Santos, E. Genetic admixture in Brazil. Am. J. Med. Genet. C Semin. Med. Genet. 2020, 184, 928-938. [CrossRef] [PubMed] 
29. Ferreira, G.D.; Fernandes, G.M.M.; Penteado, C.; Coria, V.R.; Galbiatti-Dias, A.; Russo, A.; Castanhole-Nunes, M.M.U.; Silva, R.F.D.; Silva, R.; Pavarino, E.C.; et al. Polymorphisms in xenobiotic metabolism-related genes in patients with hepatocellular carcinoma: A case-control study. Xenobiotica 2021, 51, 737-744. [CrossRef]

30. Sherratt, P.J.; Pulford, D.J.; Harrison, D.J.; Green, T.; Hayes, J.D. Evidence that human class Theta glutathione S-transferase T1-1 can catalyse the activation of dichloromethane, a liver and lung carcinogen in the mouse. Comparison of the tissue distribution of GST T1-1 with that of classes Alpha, Mu and Pi GST in human. Biochem. J. 1997, 326 Pt 3, 837-846. [CrossRef] [PubMed] 